\section{A Stable, Adjustable Voltage Source to Replace Mercury Batteries in EMs and Other Instruments}

\author{
N. W. (Woody) White \\ McDermott Technology
}

From time to time, a stable but adjustable voltage source can be quile handy. This article was prompled by a request for a replacement for mercury battery voltage references which are not only difficult to find, but are not environmentally friendly. Anoher application could be powering a 3 to 9 wolt diskman (or whatever) from a nominal 12 volt source such as an automabile. In fact, the circuit can be set to supply any wollage from 3 to 38 wolts.

The DC input voltage must be a minimum of 2 volts higher than the desired output voltage and absolutely no higher than 40 volls. The LM317 regulator integrated circuit (for less than $\$ 2$ ) is rated for up to 1.5 amperes oulput under optimum conditions (for the TO-220 package, shown in the following figure). Power dissipation in the form of heat can limit the output current to a lower value. The power dissipated can be calculated by subtracting the output woltage from the input woltage then multiplying the difference by the output current in amperes. The maximum allowable dissipation at room temperalure $\left(<30^{\circ} \mathrm{C}\right.$ ) is about 1.5 watts (I recommend somewhat less, or the use of a haat sink). For example, an input of 24 VDC and output of 9 volts yields a difference of 15 volts. If the current requirement is 0.1 amperes, then the power dissipated is $15 \times 0.1$, or 1.5 watts. In this case, a small heat sink would be a good idea.

If a suitable hat sink is used to keep the tab below $60^{\circ} \mathrm{C}$, the device can dissipate nearly 20 watts. If a heat sink is used, be sure to electrically isolate the tab (or heat sink) from ground or other circuitry. It is good practice to use a bit of heat sink compound between the back of the LM-317 and the heal sink surface.

Referring to the figure:

For proper operation the sum of R1 and $\mathrm{R}^{3}$ should be a value which draws about $8 \mathrm{ma}(0,008 \mathrm{amps})$ at the desired output voltage (Vo).

$$
R 1+R 3=V_{0} 0.000
$$

The trim potentiometer yalue ( $R 2$ ) will depend on the adjustment range desired. For most applications, a potentiometer value of $10 \%$ of the sum of $\mathrm{R} 1$ and R2 is a good starting point. Because this article is somewhat generalized, a little experimenting with resistor walues may prove necessary.

The cutput voltage $\left(\mathrm{N}_{0}\right)$ is a function of the ratio of resistors R1 and R3. A variable resistor, $R 2$, is used to trim (adjust) the output to the exact voltage desired. To calculate the approximate values of $R 1$ and $R 3$, use the following formula:

$$
V_{0}=1.25(1+R 1 / R 3)
$$

Standard value resistors are available only in cerlain fixed value steps. The dosest values to those calculated should be chosen. R2 is then adjusted to obtain the exact ratio (i.e., output vollage) required. Be sure to use stable resistors, either wirewound or metal film.

Parts layout is not critical, but for good temperature stablity the proper resistor type should be used. Also, keep them as far away as practical from heal sources. Overall stability of the voltage will depend on a number of yariables, but should typically be better than $0.25 \%$ after warm-up, and better, if the supply to the circuit is regulated and the load is constant.

The diode (D1) and capacitor (C2) are optional. The diode protects the LM317 from reverse woltages which may arise in certain applications. The capacitor (C2) will ever so sllghtly slow the regulator transient response, but can help reduce the possibility of introduced noise when the regulator is used in a location subject to strong interfering fields. For the most simple circuit, R2 may be eliminated, connecting $\mathrm{R} 1$ directly to $\mathrm{R} 3$ and then connecting that junction to the "adjust" lead of the LM317. Available standard resistor values will limit the cutput voltage values.

The LM317 is limited to a maximum of 1.5 amps. Higher current devices are awailable which work in a similar manner. The chip package is typically different in order to handle the higher current. The LM350 can supply 3 amps and the LM33B is rated to 5 amps. Data on these devices, as well as the LM317 can be found at the following National Semiconductor www site:

hitp:/Www.national.comicatalog/AnalogRegulators_LinearRegulatorsStandardNP N_PositiveVoliegeAdjustable.himl

\section{PARTS LIST}

Catalog numbers referenced here are from Digi-Key: (800)344-4539 or http://www.digikey.com. I have no vested interest in this supplier, but have been salisflied with their performance over several years and they carry all the needed parts.

LM317: (LM317AT-ND), Adjustable positive voltage regulator (see figure for pin-out). PT\# 92448-ND

D1: 1N4002, 1 Amp, 200 wolt (observe polarity when installing). PT\# 1N4002GICT-ND

R1, R3: Exact values dependent on calculations. For best stability, precision wire wound resistors are specilied. Other types may be substituted if precision stability is not a concern. PT\# SC1A(value)-ND or SC3D(value)-ND

R2: Trimmer potentiometer, Bourns series 3059P, Value dependent on desired adjustment range and $V_{0}$ (see calculations). PTH 3059P(value)-ND

C1: $0.1 \mu F, 50$ volt minimum, monolithic ceramic. PT\# P4887-ND

C2: $220 \mathrm{pF}, 50$ volt minimum, monolithic ceramic. PT\# P4804ND

C3: $2.2 \mu \mathrm{F}, 50$ volt, electrolytic (observe polarity when installing). PT\# P6790-ND

Periboard: Epoxy-Glass or phenolic board with pre-puncher hole arrays. Available from Digi-Key, Manufacturers: Vector Co. or Keystone. A $4.5^{\circ} \times$ $6.5^{\circ}$ (should be sufficient for 3 or more circuits) is PT\# V1043.

Heat Sink: A good source for small heat sinks is a dead compuler monitor. Digi-Key also carries Aavid brand heat sinks. Size will depend on heat load and ambient temperature. They also carny heat sink compound.

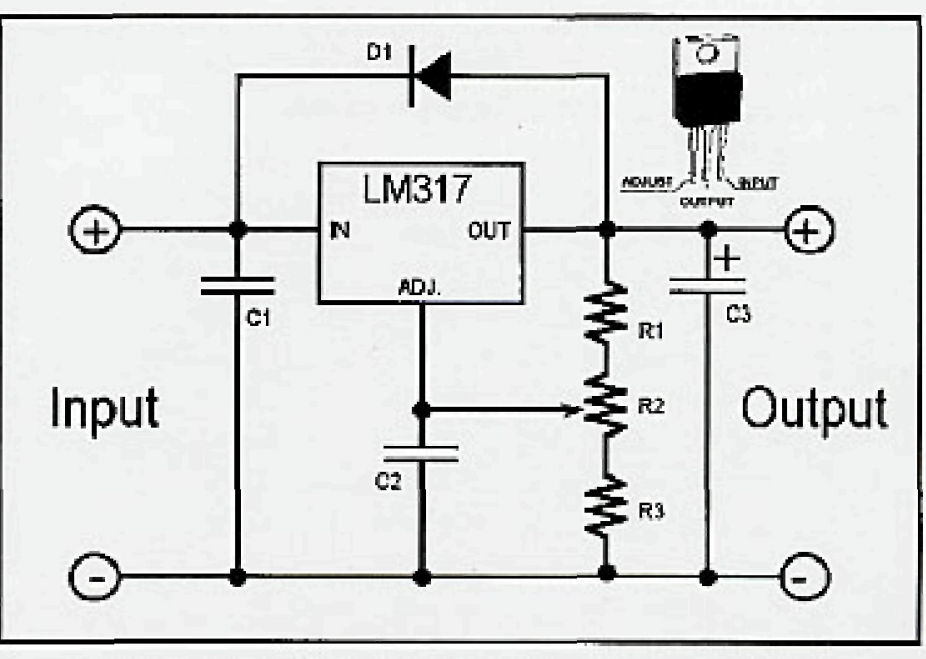

Circuit diagram for stable voltage source to replace mercury batteries

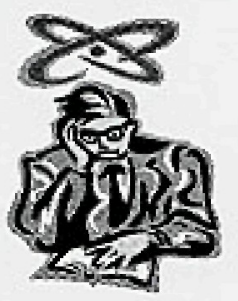




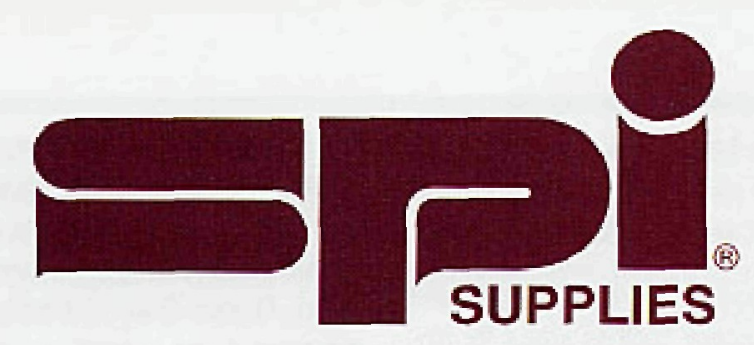

f File Edit Diew Go Bookmarks Options Directory Help

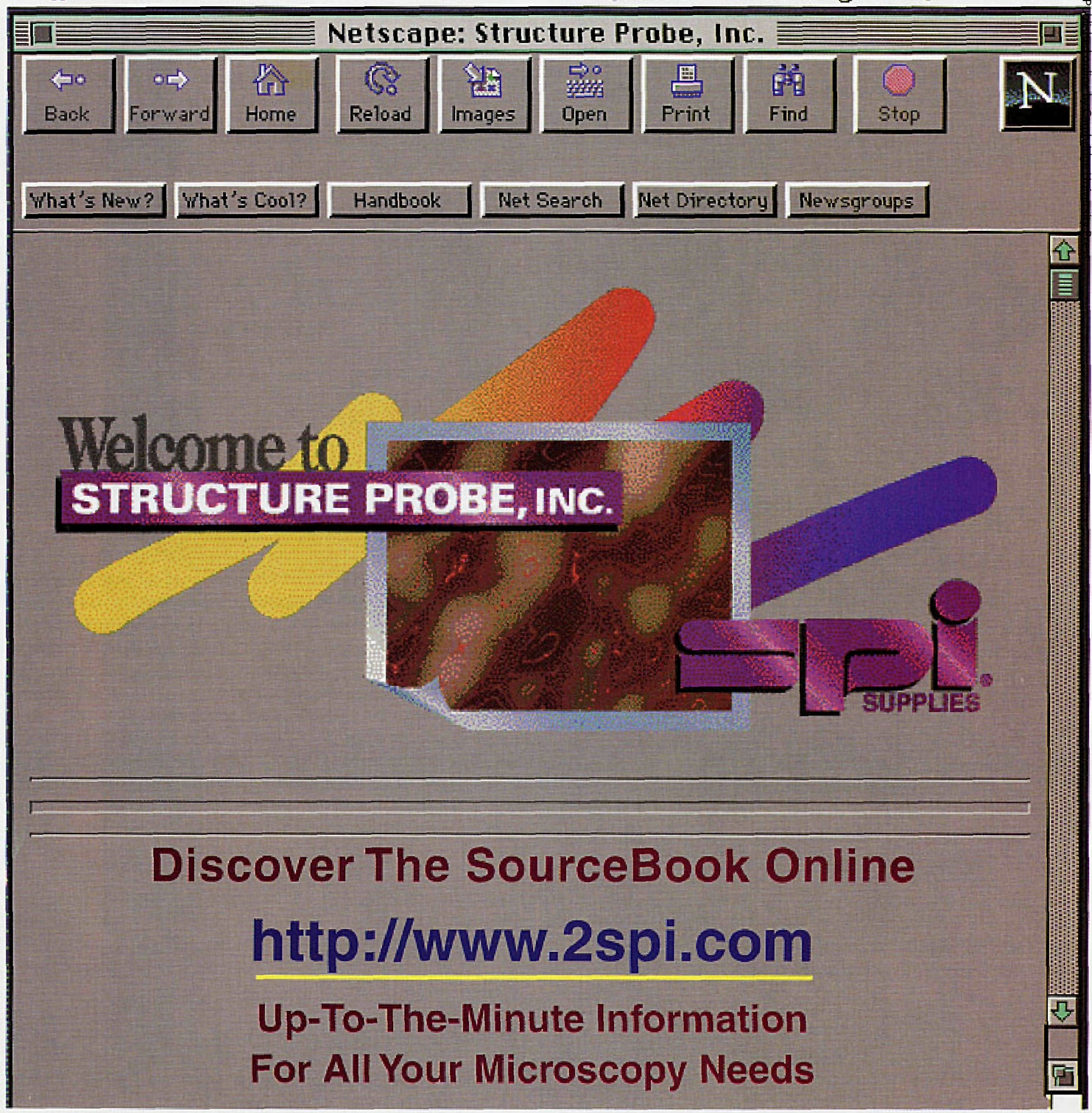

SPI Supplies Division of STRUCTURE PROBE, Inc.

P.O. Box 656 - West Chester, PA 19381-0656 USA

Ph.: 1-610-436-5400 • 1-800-2424-SPI (U.S. only) • FAX: 1-610-436-5755 • E-mail: spi2spi@2spi.com 